\title{
Stratum Basale
}

National Cancer Institute

\section{Source}

National Cancer Institute. Stratum Basale. NCI Thesaurus. Code C33623.

The deepest layer of the epidermis, which is adjacent to the dermis, and which is the primary location of mitotically active cells of the epidermis. 